THE

CENTER

FOR

STATE

AND

LOCAL

FINANCE

\section{Financing Outdoor Recreation}

H. Spencer Banzhaf V. Kerry Smith

Working Paper 20-01

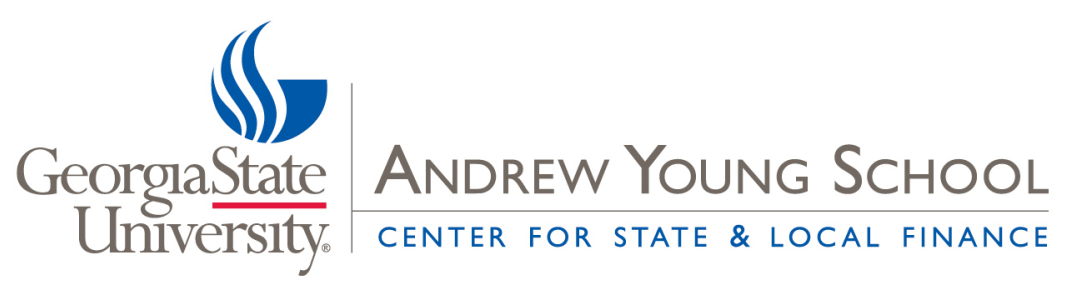


We thank the Property and Environment Research Center (PERC) for support of this research. We also thank Nathan Chan, Cathy Kling, Matt Kotchen, and participants in a PERC workshop for helpful comments.

cslf.gsu.edu

Financing Outdoor Recreation 


\section{The Center for State and Local Finance}

WORKING PAPER 20-01

\section{Financing Outdoor Recreation}

H. SPENCER BANZHAF

V. KERRY SMITH

July

2020

The Center for State and Local Finance

Andrew Young School of Policy Studies

Georgia State University

Atlanta, Georgia 30303

United States of America

Phone: (404) 413-0137

Fax: (404) 413-0248

Email: paulbenson@gsu.edu

Website: cslf.gsu.edu

Copyright 2020, the Andrew Young School of Policy Studies, Georgia State University. No part of the material protected by this copyright notice may be reproduced or utilized in any form or by any means without prior written permission from the copyright owner.

cslf.gsu.edu

Financing Outdoor Recreation 


\section{The Center for State and Local Finance Andrew Young School of Policy Studies}

The Center for State and Local Finance's (CSLF) mission is to develop the people and ideas for next generation public finance by bringing together the Andrew Young School's nationally ranked faculty and the broader public finance community. CSLF conducts innovative, nonpartisan research on tax policy and reform, budget and financial management, education finance, and economic development and urban policy. Additionally, it provides premier executive education in public finance for state and local finance officials and works with local and state partners on technical assistance projects on fiscal and economic policy.

CSLF Reports, Policy Briefs, and other publications maintain a position of neutrality on public policy issues in order to safeguard the academic freedom of the authors. Thus, interpretations or conclusions in CSLF publications should be understood to be solely those of the author(s).

For more information on the Center for State and Local Finance, visit our website at cslf.gsu.edu 


\section{Introduction}

The National Park Service (NPS) has argued that our national parks face a growing crisis because of their inability to address deferred maintenance needs. By one account, the parks overall had a backlog of $\$ 11.9$ billion in FY2018 (CRS 2019a). Likewise, the Bureau of Land Management (BLM), Fish and Wildlife Service (FWS), and Forest Service (FS) report deferred maintenance amounting to \$7.5 billion in 2018. Comparison of these estimates to those for earlier years (in constant dollars) suggests the problem is not new. Indeed, there have been high levels of deferred maintenance for these agencies since at least FY2009. The picture is more mixed at the state level but there are certainly some states with significant maintenance backlogs.

There are three main strategies for meeting these revenue needs. The first is to fund public lands through general revenues. The second is to raise the needed revenue through entrance fees, which, conceptually, can be thought of as a tax on trips to the destination. The third strategy is a gear tax, which would raise the revenue through a tax on gear associated with recreation.

The first strategy, using general revenues, is consistent with the standard emphasis in public finance focusing on efficiency. Following Ramsey's (1927) classic paper, tax analysis would begin by asking about revenue needs and then, separately, how to distribute the burden across an excise tax system based on its efficiency, which in turn depends on how it distorts the relative demands for each good. From this perspective, dedicated taxes linking revenue from a particular source to a particular purpose are simply unnecessary constraints on the problem. See Myles (1995 p. 105) for a textbook treatment and Walls (2013) for a discussion in the context of funding parks.

However, this also is largely the status quo approach. Between FY2010 and FY2019, annual appropriations for NPS operations have ranged between $\$ 2.4$ and $\$ 3.0$ billion in 2010 dollars (CRS 2019c). Yet these appropriations have not addressed the maintenance backlog. Although Congress recently authorized about $\$ 900 \mathrm{~m}$ in annual revenues from offshore oil and gas leases on federal lands, if past practice continues these funds will not be fully expended. ${ }^{1}$ It appears that the appetite to raise taxes on the general public-or to borrow through deficit financing from future generations - is not sufficient to take care of federal lands.

Accordingly, in this paper, we evaluate the alternative strategies of entry fees and the gear tax. Although neither has provided as much funding as general revenues, both strategies have been used to some extent. In 1996, the US Congress authorized the "Fee Demonstration Program," in which certain units of the NPS, FS, BLM, and FWS could charge fees to users, with $80 \%$ of the revenues staying in the local unit, thereby incentivizing managers to make the most efficient use of their funds. Fees are collected at 184 NPS units (46.3\% of all units), 3,759 NFS units (13.9\%), 430 BLM units with developed recreation (11.9\%), and 141 FWS refuges (25.4\%) (CRS 2015). Together, the agencies collected approximately $\$ 350 \mathrm{~m}$ in

\footnotetext{
${ }^{1}$ For discussion of how the Land and Water Conservation Fund (where funds are accumulated) is used in practice, see CRS (2019b). As of this draft, Congress is debating permanently funding the LWCF.
} 
entrance fees in $2017 .^{2}$ For its part, the gear tax would essentially be an extension of the PittmanRobertson and Dingell-Johnson Acts, which authorize taxes on hunting and fishing gear to other types of recreation related equipment. These taxes generate over $\$ 1 b$ annually for conservation programs. ${ }^{3}$

Both recreation fees and the gear tax involve collecting revenue from private activities - trips to public lands and purchases of gear, respectively - that are complements to the services provided by public lands and, potentially, to the specific services provided by the investments funded through those revenues. This complementarity has two implications. First, it has implications for the efficiency of the taxes.

Conventional treatments of optimal taxation do not consider how the revenue would be used and, in particular, whether the revenues support public goods that are either substitutes or complements to one or more of the private goods being taxed. In these cases, there is the conventional direct effect of the tax, distorting market signals, and the feedback effect of the supported good on the demand for the taxed goods. Second, complementarity relationship suggests that services are being supported by taxing those who benefit from them. The benefit, or user-pay principle, suggests that those who benefit from a publicly provided good should be the ones to bear the burden of funding it. ${ }^{4}$ Taxing gasoline to fund roads and property taxes to fund local amenities are examples. Such dedicated tax systems bring the financing of public goods comparatively closer to private markets, where users generally pay for the services because they are the ones who benefit, as with private goods.

In this paper, after reviewing the economics of bundling and weak complementarity in Section 2, we analyze (in Section 3) the efficiency and distributional effects of increasing, jointly, a gate fee and enhancing the quality or amount of a public good that is funded by the fee revenues. To simplify the analysis, we first assume trips to public lands are "weak complements" to the services provided by public lands. This condition means that households have no value for the planned investments in those public lands unless they make trips to the sites (Mäler 1974, Smith and Banzhaf 2004). For example, they do not value improvements in trails or stocking streams with fish unless they come to hike or fish. We show that, under this condition, there is a sufficient statistic determining whether an increased gate fee, with revenue reinvested in the site, improves visitors' welfare: Namely, an increase in the number of trips to the site.

Next, in Section 4, we extend this logic to the gear tax. Like the gate fee, the gear tax can be thought of as taxing a private good that is a weak complement to public lands: Households do not value trail

\footnotetext{
${ }^{2}$ Data compiled from NPS (2018), USFS (2017), and CRS (2015). We use 2017 estimates from the 2018 budget requests from the NPS $(\$ 257 \mathrm{~m})$ and NFS $(\$ 65 \mathrm{~m})$ respectively, plus an estimate from CRS $(2015)$ that these two agencies account for $92 \%$ of the total. The authorization for charging these fees expires in September 2020. See Fretwell (1999) and CRS (2015) for overviews of the program.

3 These laws raise $\$ 1.1 \mathrm{~B}$ per year from an $11 \%$ ad valorem tax on guns, bows, and ammunition and a $10 \%$ tax on fishing gear and boat fuel. See Williams (2010) for an overview of these programs and US DOI (2018a,b) for recent dollar figures. A similar proposal for a gear tax was floated during the Reagan administration, when it was sometimes referred to as the "bird seed tax" (Loomis and Olson [1985]).

${ }^{4}$ The benefit approach has been a textbook principle in public finance since Musgrave's (1959) discussion. It had its full realization in Lindahl's voluntary exchange logic and the associated individual pricing of public services.
} 
maintenance without boots, or value fish stocks without a rod. Unlike the gate fee, however, the gear tax now involves sellers and a supply price that will respond endogenously to the tax. Nevertheless, we show that, with weak complementarity and oligopolistic competition, our test still holds: If the quantity demanded for the gear increases on net from the joint effect of the tax and the investments it funds, then there is a potential Pareto improvement. More surprisingly, households and firms are better off. That households are better off may not seem surprising, as this result is similar to the gear tax, and the increased elasticity of the supply side can only help the demand side.

That firms are better off may be more surprising. As we discuss in more detail, the basic intuition for this result comes from the way private and public goods are "bundled" so that the tax leverages the benefit principle. In general, private markets work because entrepreneurs find a way to provide valuable services at a price that leaves both sides of the transaction better off. As Anderson and Leal (2001), Anderson and Parker (2013), and Heal $(2000,2003)$ discuss, entrepreneurs can still perform this function for a public good when it is bundled to a private good. The bundling overcomes the excludability problem. For example, if households do not value wildlife unless they come to visit it, entrepreneurs can invest in wildlife and recoup their investment through the increased demand for a hotel or a tour, which are excludable private goods. As Heal (2003) emphasizes, this logic is most compelling when the entrepreneur is a monopolist, as then there is no free rider problem in the provision of the services. However, in principle, this problem could be overcome by working cooperatively (Ostrom 1991). The gear tax simply plays this coordinating role: If the monopolist would voluntarily make the investment, a group of firms can be "forced" to do so through the tax, and still be better off.

Section 5 relaxes some of the modeling assumptions used in our simplest analysis. In particular, we relax the weak complementarity assumptions and show that our simple test is still a sufficient (but not necessary) condition for both sides of the market to be better off.

Section 6 assembles a variety of empirical information needed to use our first order approximation to develop back-of-the-envelope calculations offering a range of values for the link between a quality improvement and the welfare neutral price increase. Finally, the last section draws together research needs and the implications of what we know for addressing the questions associated with funding park needs in the future.

\section{Bundling and Weak Complementarity}

Economists often make a sharp distinction between private goods, which can be provided by markets, and public goods, usually provided by governments. In many cases, however, households use a "bundle" of public goods and private goods together, to enjoy the services they jointly provide. Outdoor recreation is an example of such bundling. To enjoy a recreation trip, a household bundles together the publicly provided resource (the scenic vistas and built amenities) and their time along with some private goods and services, such as transportation and gear (whether generic to many outdoor activities, like outdoor clothing and boots, or specialized equipment like kayaks, fishing gear, etc.). 
This bundling can be modeled as complementarity between the public and private goods. Of course, two private goods exhibit complementarity when a lower price for one leads to greater demand for the other. For bundles of public and private goods, complementarity can be understood as arising when an increase in the availability of a public good leads to an increase in the demand for the private good and, symmetrically, when a lower price for the private good leads to a higher marginal willingness to pay for the public good (Madden 1991).

A particularly important type of complementarity relationship between public and private goods is known as weak complementarity (Mäler [1974], Smith and Banzhaf [2004]). Weak complementarity is defined as a situation in which the public good has no value to people unless they also consume positive levels of the linked private good (the weak complement). For example, weak complementarity would hold if people do not care about the ecosystem services at a park unless they take trips to it. In other settings, people might not care about local school quality in a neighborhood unless they have housing in the neighborhood; they might not care about local roads unless they drive on them; etc. But the reverse need not hold. The private good's value does not have to be exclusively associated with the services of the public good. People can value spending time watching sports or bowling without using their leisure time by taking trips to a park.

Economic measures for changes in the amount of the public good exploiting this connection are sometimes labeled use values. Thus, weak complementarity rules out non-use values, i.e., values households have for the investment even if they never use it in any instrumental sense. ${ }^{5}$ This assumption may be problematic for some policy questions, such as the preservation of unique resources such as Yellowstone or the Grand Canyon, or investments that protect ecosystems, where non-use values are important. However, for present purposes, our focus is on funding for deferred maintenance and ongoing operations, not preservation. Though some of these investments may protect ecosystems, many involve more pedestrian objectives like maintaining bathrooms, trails, and campsites that are linked to recreation use. In any case, even if there are nonuse values, we can say that weak complementarity holds for that portion of households' total value linked to recreation.

Weak complementarity is useful because it assures that, when there is an investment in a publicly provided asset, the change in households' Hicksian consumer surplus for their consumption of the private good (that is a weak complement) will be equal to their Hicksian willingness to pay (WTP) for that investment (Mäler [1974]). Figure 1 depicts the change in consumer surplus for the private weak complement due to this type of investment. It shows the marginal cost of the private good $x$ (e.g. the travel cost of trips to the park) and two Hicksian demand curves for an individual. The lower demand curve shows the quantity of the private good (trips) that would be demanded when income is adjusted to leave the consumer at the same level of utility, when evaluated at a baseline level of environmental or resource quality, $q^{0}$. The upper demand curve shows the corresponding demand at a higher level of

\footnotetext{
${ }^{5}$ Consequently, the assumption limits "the extent of the market" to the set of users, even though the set of people who would value the investment is larger.
} 
environmental quality, $q^{1}$. (We are assuming that the public and private goods are ordinary complements as well as weak complements, with people more likely to participate in recreation when the quality of the recreation experience is better, so the improvement in environmental quality increases the quantity of recreation demanded at a given price.)

\section{Figure 1. Increased Value of the Private Good Caused by Improved Public Good}

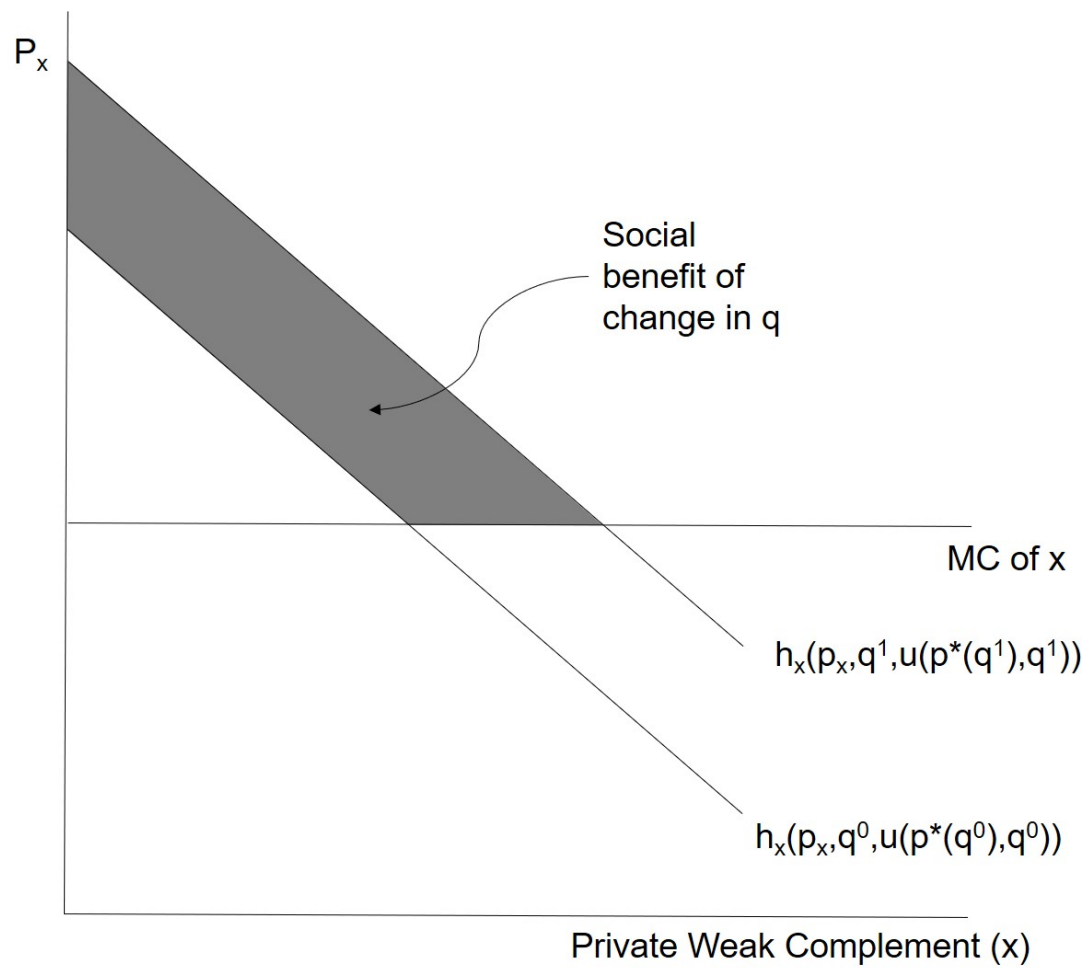

Weak complementarity guarantees that the shaded area between these two lines, up to the level consumed, is the individual's value (or at least the recreational value) of the improvement in $q$. Consider now Figure 2, which depicts the marginal cost of providing the public good $q$ against the marginal social value of a little more $q$. The shaded area in Figure 2 is the (gross) value of the improvement in the public good from $q^{0}$ to $q^{1}$. Weak complementarity guarantees that the two shaded areas in the two figures are the same, for each individual. Consequently, the respective sums across individuals of the two areas are the same, and the aggregate value of the investment is equivalent to the change in aggregate consumer surplus for the private weak complement. 


\section{Figure 2. Value of the Improvement in the Public Good}

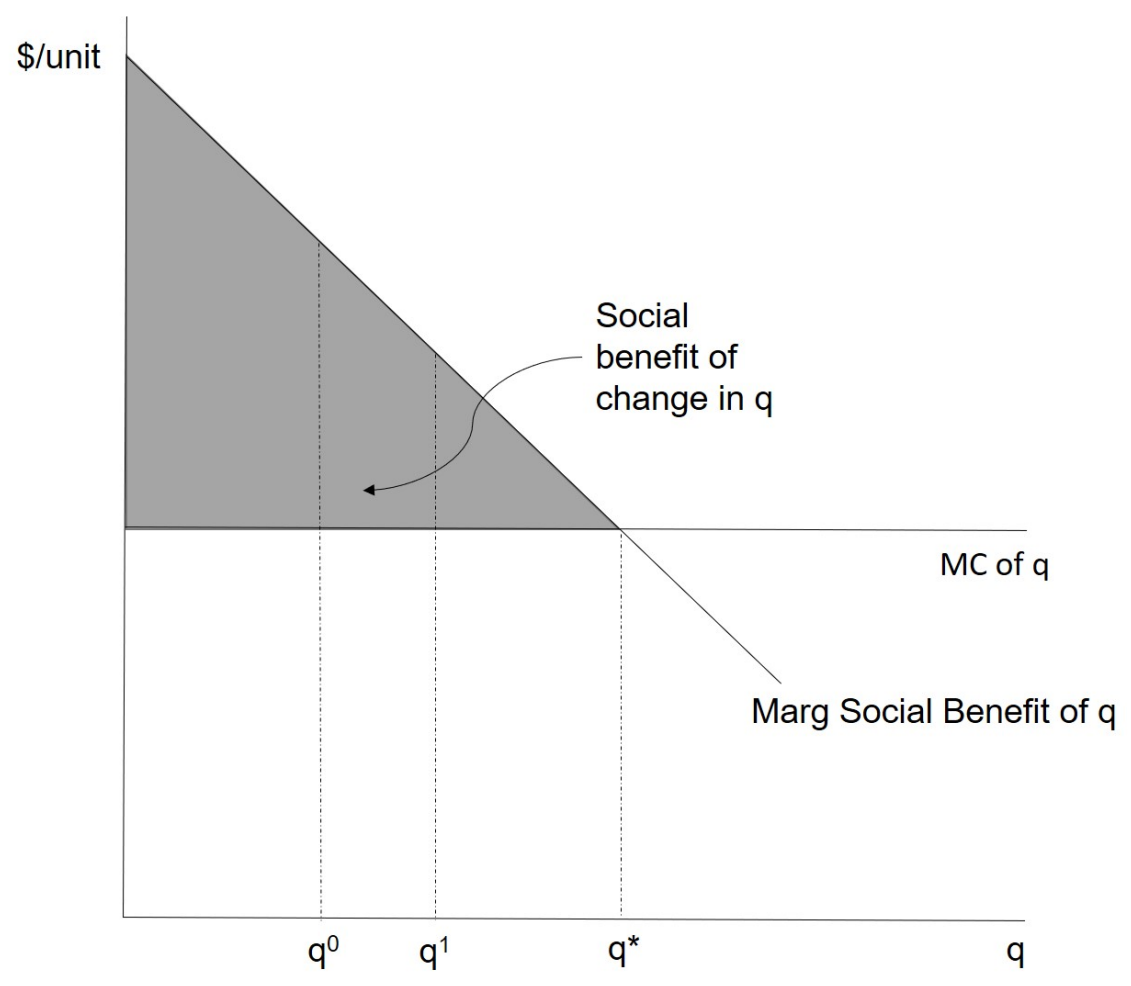

A further consequence of this equivalence is that the value of the environmental services (Figure 2) can actually be captured in the market for the private good (Figure 1), wherever excludability is possible. For example, to the extent households only have recreation values for environmental resources, they can be excluded from enjoying them because they can be excluded from entering those areas. This bundling creates incentives for private parties to provide environmental services (Anderson and Leal [2001], Anderson and Parker [2013], Heal [2000, 2003]). As we discuss below in Section 4, it similarly creates the possibility that sellers of gear can benefit from a gear tax. When households have non-use values for the quality improvements associated with investments in a park, they cannot entirely be excluded from enjoying them, making it more difficult for private parties to capture the full value. Nevertheless, as we discuss in Section 5, partial values may be sufficient.

In practice, environmental values can be captured in private markets because weak complementarity implies there is a hypothetical increase in the price of the linked private good that exactly compensates for the improvement in the public good, leaving the consumer indifferent to the combined change (Willig [1978], Smith and Banzhaf [2004)]). Any actual price increases less than this level would then leave consumers better off. Thus, instead of measuring value through income adjustments associated with willingness to pay as economists usually do, one can measure value through price adjustments. However, 
the "right" price adjustment will differ for each consumer. ${ }^{6}$ Figure 3 reproduces the "fanned" indifference curves from Smith and Banzhaf (2004), which display the way weak complementarity affects the tradeoff between a private good ( $x$ in the diagram) and a numeraire good $(Z)$. The non-market good is $q$. Three indifference curves are displayed. $\bar{U}\left(q^{0}\right)$ depicts the baseline situation, with the consumer's optimum at point B. The dashed indifference curve $\widetilde{U}\left(q^{1}\right)$ indicates that at a higher level of $q$ (with $q^{0}<q^{1}$ ), the consumer obtains higher utility and also purchases more of the private weak complement at point $E$. The indifference curve $\bar{U}\left(q^{1}\right)$ depicts the combinations of $x$ and $Z$ that leave utility unchanged at the initial level when quality increases. The two solid indifference curves intersect at the vertical axis because at that point $x=0$, and weak complementarity implies that $q$ has no value to the individual without $x$.

\section{Figure 3: Fanned Indifference Curves and Weak Complementarity}

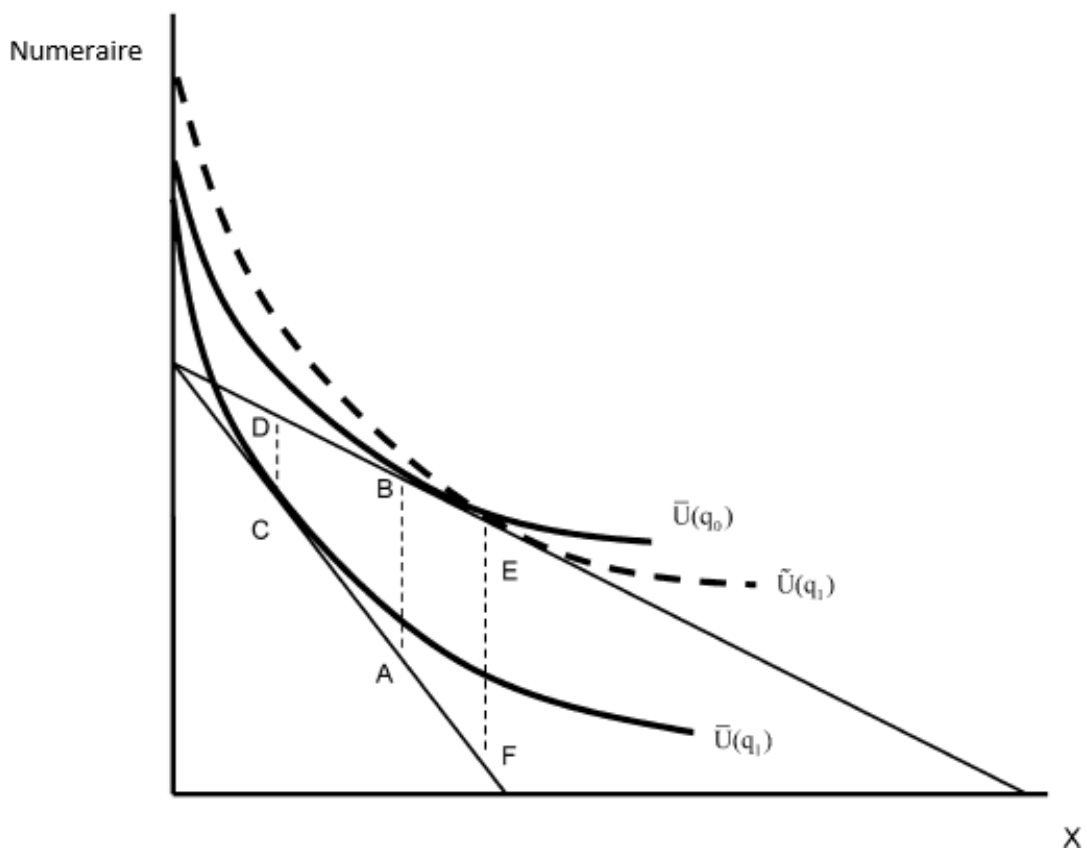

The figure illustrates that there is a hypothetical increase in the price of the weak complement that would just compensate for the quality improvement and bring the consumer from $\widetilde{U}\left(q^{1}\right)$ to $\bar{U}\left(q^{1}\right)$, with equilibrium at point $C$. This price increase represents the source for the potential revenue gain to suppliers of the private good from the investment. In addition to giving them an incentive to provide the investment themselves, it creates the possibility that they can benefit from it even if their own sales are taxed to provide it, a point we return to in Section 4.

\footnotetext{
${ }^{6}$ Thus, Heal (2003) shows that price discrimination is generally required for a firm to have the full incentive to make the investment. As Kotchen (2013) notes, there is a connection between this framework and Lindahl (1919 [1958]) pricing, in which each household pays its marginal value for the public good. Here, that household-specific price for the public good is captured in the market for the weak complement.
} 


\section{The Economics of Gate Fees}

In this section, we apply the logic of Figure 3 to the economics of gate fees. In particular, we show that when trips to public lands are a weak complement to the services provided by the investment in these lands, then there is a fee increase that, when combined with the investment, leaves households indifferent. If the actual fee required to fund the investment is lower than this critical level, households are better off. To a first-order approximation, this criterion is equivalent to observing an increase in the number of trips from the joint effect of the increased fee and the increased investment funding with the resulting revenue. This equivalence makes the connection empirically tractable.

We model gate fees as comparable to a tax on trips. Trips are an especially convenient activity to analyze in this way, because their price is set by distance between a household's home and the site and by permile transportation costs, both of which are plausibly exogenous to the policy. ${ }^{7}$ Thus, we can view trips to the site (which we denote by $x$ ) as having perfectly elastic supply at a pre-tax price of $p_{x}$. The price of a composite of other consumption goods is normalized to 1 . Let $q$ be the quality of the park that is visited. Income is fixed and designated by $m$. Let $V($ ) represent the indirect utility function for a representative household. Finally, assume that trips are non-rival, so that, if lump sum taxes were available, the optimal gate fee would be zero. ${ }^{8}$

Equation (1) provides the indirect utility function expressed in general terms:

$$
V\left(p_{x}, q, m\right)=\bar{U}
$$

Here, $\bar{U}$ designates the fact that our analysis begins with a baseline level of utility.

Now consider a policy that jointly imposes an entry fee $t$ and provides a change in quality $\Delta q$ from reinvesting on site the resulting revenue. To a first order approximation, the change in utility is:

$$
\Delta V \approx V_{p_{x}} t+V_{q} \Delta q
$$

Dividing both sides by the marginal utility of income $V_{m}$, substituting using Roy's identify for $-V_{p_{x}} / V_{m}=$ $x$, and defining the marginal willingness to pay for $q$ by $\pi=V_{q} / V_{m}$, we have:

$$
\Delta V>0 \leftrightarrow t x<\pi \Delta q
$$

\footnotetext{
${ }^{7}$ The largest share of the costs of a trip is associated with the opportunity costs of time. Conventional practice assumes the opportunity cost of time is a fixed fraction of an individual's wage and the labor/ leisure choice is taken as given.

8 This assumption is largely for simplicity and our results could be generalized to account for such costs. Rivalry would imply there are opportunity costs for serving additional trips to a site. For example, congestion is a concern in some contexts. Additionally, trips might require additional facilities maintenance. Unfortunately, data on maintenance is available only at an aggregate level (GAO [2016], Table 2). Using ten years of data by budget category and fund sources, we found that maintenance for facility operations, routine services using recreation fees, and for the Federal Lands transportation components were all significantly related to visitation levels.
} 
This simply says that utility is increasing if and only if the fee paid, $t x$, is less than the value of the investment, $\pi \Delta q$. This obviously must hold in general, to a first order approximation.

The assumption of weak complementarity brings additional insight. For any arbitrary $\Delta q$, weak complementarity guarantees that there exists a $t^{*}$ such that $\Delta V=0$ (Willig [1978], Smith and Banzhaf [2004]). Returning to Equation (2), this is given by:

$$
t^{*} \approx-\frac{V_{q}}{V_{p_{x}}} \Delta q
$$

More generally,

$$
\Delta V>0 \leftrightarrow t<-\frac{V_{q}}{V_{p_{x}}} \Delta q \approx t^{*}
$$

That is, welfare improves if and only if, for any given $\Delta q$, the actual fee $(t)$ is less than the critical value $t^{*}$. Expression (5) can be interpreted more intuitively if we again divide the numerator and denominator of the right-hand term by the marginal utility of income:

$$
\Delta V>0 \leftrightarrow t<=\frac{\pi}{x} \Delta q
$$

As $\frac{\pi}{x}$, or the marginal willingness to pay for quality per trip, is a commonly estimated parameter in travelcost modeling, this condition is, in principle, empirically verifiable. The condition gives us a starting point for determining a neutral tax from the perspective of the representative household. Thus, if $\Delta q$ can be produced by the park agency with a gate fee less than $t^{*}$, then the welfare of the representative visitor is increased by the policy. Although in the context of public lands we are discussing a kind of public finance mechanism, note the close connection between this result and the earlier discussion of ecotourism: A market in ecosystem services will succeed if entrepreneurs can charge a price for a linked private good high enough to cover the costs of ecosystem improvements but low enough to attract customers.

However, there is another aspect of this relationship. So far, we have considered simultaneous but essentially arbitrary increases in the fee $(t)$ and in the public good, $\Delta q$. In practice, the ability to realize the $\Delta q$ depends on the aggregate revenue raised from the fee increase or $t x N$, where $x$ is the average 
number of trips per user and $N$ is the number of users. We can use a simple characterization with $\Delta q=$ $N t x / p_{q}$, where $p_{q}$ is the price of producing a unit of $q .^{9}$

Substituting this relationship into Expression (6), the policy increases aggregate welfare if and only if:

$$
t<\frac{\pi}{x} \frac{N t x}{p_{q}}
$$

or,

$$
p_{q}<N \pi
$$

This test seems a straightforward application of the Samuelson rule, comparing the supply price of the public good to the sum of the marginal willingness to pay. This result may be surprising, as we are not using a lump-sum tax. At first, it may appear that in taking our first-order approximation we have simply assumed away deadweight loss in the market for trips. In fact, the result stems from the fact that weak complementarity guarantees that prices and marginal willingness to pay can be compared in the same space. Our approximation merely simplifies things by translating willingness to pay for quality into a parallel shift in the demand curve for the private good. With this simplification, the above condition guarantees that there is no (net) deadweight loss in the private good to worry about, even though we are not using a lump-sum tax. Of course, we are asking whether a given policy proposal $(t, \Delta q)$ is welfare improving, not whether it is optimal. If lump sum taxes were available, the policy would indeed involve deadweight loss relative to that first-best alternative, as the number of trips would be even higher in that case. ${ }^{10}$ Chan and Kotchen (this issue) evaluate alternative taxation schemes from that perspective.

Our approach can be illustrated with Figure 1. An increase in q, taken in isolation, increases the inverse demand curve as shown. Our first-order approximation implies the inverse demand curve shifts up, in parallel, by $\pi \Delta q / x$, or the WTP for $\Delta q$ per trip. By weak complementarity, the resulting increase in consumer surplus is equal to the value of an increase in $q$. Just as we can depict the value of $\Delta q$ in the demand for trips, so we can depict the Hicksian-equivalent price adjustment or gate fee. The fee would shift the cost of trips up by $t$. If the costs of a trip increased by the same amount that the demand curve

\footnotetext{
${ }^{9}$ So the feasibility of realizing $\Delta q$ depends on the tax base, including the trips per household $x$ and the extent of the market $N$, and the price of $q$. Our analysis leading to equation (6) does not discuss the point of evaluation for the partial derivatives leading to $\frac{\pi}{\Delta q}$. At the travel costs without the added fee, $x$ corresponds to initial average number of trips per user. With the fee and $\Delta q$ the new equilibrium number of trips will be different. Thus, in principle, there is also the second-order consideration of the feedback effect of the tax and quality change on the revenue. Our analysis using first-order effects ignores this feedback. However, this feedback effect can never overturn our test. If the fee and the reinvested revenue assessed on the baseline number of trips jointly increase the number of trips (our condition for increased welfare), then that can only increase the associated $\Delta q$, thus further increasing welfare. If, on the other hand, they decrease the number of trips (our condition for reduced welfare), then that can only decrease the associated $\Delta q$ through the eroded tax base, thus further decreasing welfare. Our sufficient statistic still holds.

10 This case differs from textbook logic because whereas with the lump sum tax the policy simultaneously reduces income and increases the public good services, here it changes the price of a weak complement and increases the public good services. The relative size of second order effects will figure into assessing the deadweight losses.
} 
increased, the number of trips would be unchanged and consumer surplus would be unchanged. This is precisely what would happen if the fee were $t^{*}$. If the actual fee supporting $\Delta q$ were less, welfare would be higher on net.

Viewing the gate fee as an excise tax on trips, we could also follow the logic often used to describe the effects of a per unit tax and illustrate its effect by shifting the demand curve down by $t$ and leaving the supply unchanged. The above analysis suggests, then, that the key question is whether, on net, the demand curve shifts up or down from the joint effect of the excise tax on trips and the quality improvement. As a shift up in a demand curve, with fixed supply, is associated with an increase in trips, we have the following proposition:

Proposition 1. Under weak complementarity, to a first-order approximation, welfare increases from a combination of a dedicated gate fee and the associated increase in public good services if and only if the quantity demanded implied by the Hicksian demand for trips increases on net.

Such a test could be implemented with standard travel cost models, which predict the effect of costs on trips, if they also can account for the quality change at stake. Our use of the term "associated" is intended to highlight the fact that the aggregate revenue raised from the gate fee must cover the cost of the increase in services.

Under an additional restriction, known as the Willig (1978) condition, this insight leads to an extremely simple ex-post empirical test for a welfare improvement. The Willig condition guarantees that the Marshallian variant of the change in consumer surplus for the private weak complement, depicted in Figure 1, also is equivalent to the Hicksian consumer surplus in Figure 2. It is equivalent to restricting the price adjustments discussed above to be invariant to income:

$$
\frac{\partial(\pi / x)}{\partial m}=0
$$

(See Bockstael and McConnell [1993] and Smith and Banzhaf [2004, 2007] for additional discussion.) Under this restriction, we can use a net change in the Marshallian consumer surplus for the private weak complement as the basis for our assessment-and, hence, observed changes in the Marshallian demand.

Proposition 2. Under weak complementarity and the Willig condition, to a first-order approximation, welfare increases from a combination of a dedicated gate fee and the associated increases in public good services if and only if the Marshallian quantity demanded for trips increases on net.

Thus, ex post, if we observe an increase in trips ceteris paribus, we have an increase in welfare.

\section{The Gear Tax}

The previous argument leads naturally to a strategy for analyzing the gear tax. The difference between the gate fee and the gear tax lies in the fact that (i) we must account for the welfare of sellers as well as 
consumers; (ii) we can no longer assume a perfectly elastic supply as we could in the case of exogenous travel costs, so we must account for market price adjustments; and (iii) the assumption of complementarity may not be as plausible for some gear in the tax base as for trips. In this section, we first account for points (i) and (ii), maintaining the assumption of complementarity. In Section 5, we relax that assumption as well.

In principle, a gear tax can increase welfare for both consumers and sellers, if it results in a large enough quality improvement in the parks. Figure 4 illustrates the basic argument. It is similar to Figure 1, but we now have added a supply side that responds to price, instead of fixing travel costs at an exogenous level. Let $D^{0}$ represent baseline market demand, as before. Let $D^{\tau}$ represent the demand curve after it is shifted

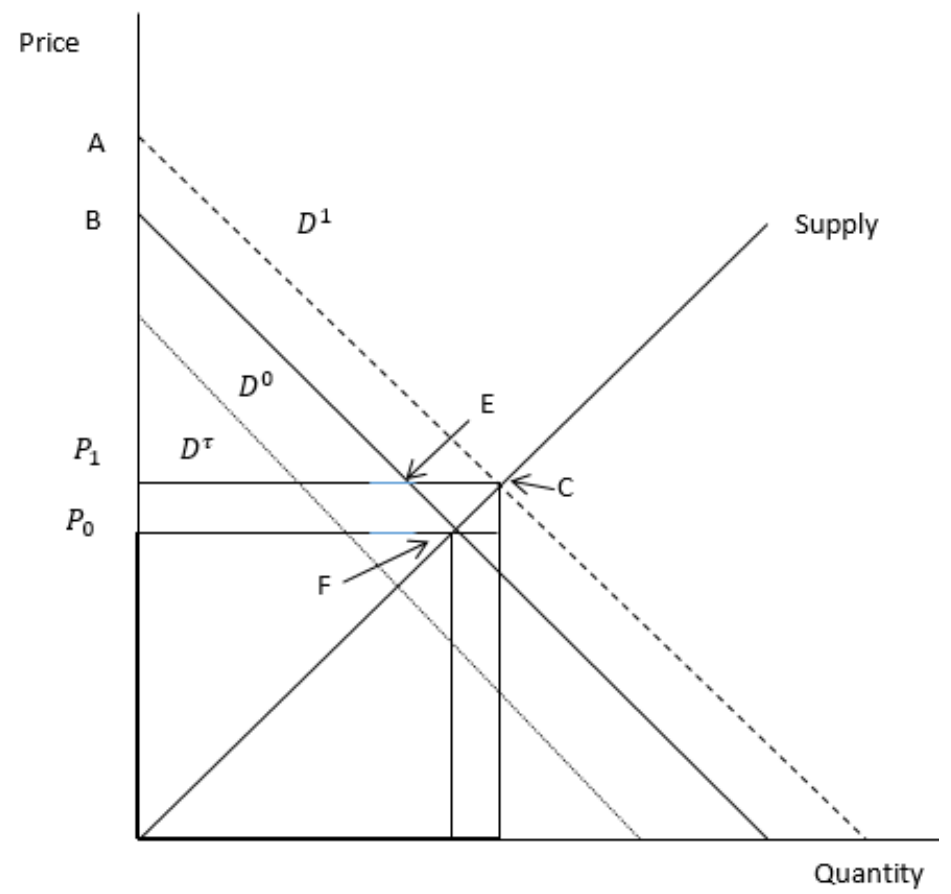

down by the amount of the excise tax on gear, taken in isolation. Let $D^{1}$ represent the ex post demand curve after the revenue is used to improve the quality of one or more parks; it shows the net increase in demand from the tax and the quality effects. Here, we show a case where there is a potential Pareto improvement, with demand shifting up on net. As shown in this diagram, both consumer surplus and producer surplus increase. After the tax and the increase in park quality, as a result of using tax revenue for this purpose, the equilibrium price increases from $P_{0}$ to $P_{1}$. Consumer surplus increases by ACEB and producer surplus by $P_{1} C F P_{0}$. Thus, the gear tax can be a strict Pareto improvement, not simply a potential Pareto improvement.

\section{Figure 4. Joint Effects of Gear Tax and Quality Change}

Figure 4 captures the basic intuition of our argument, but essentially assumes perfect competition. Arguably, perfect competition is an unrealistic assumption, as there are many large purveyors of gear with market power. Market power, in turn, raises the question of whether equilibrium prices would 
adjust in a way to lower welfare for one group. In fact, in this sub-section, we demonstrate that the basic logic continues to hold under Cournot competition.

Consider the case of $J$ symmetric firms, each with a quadratic cost function for producing a quantity of gear $x_{j}$ :

$$
c\left(x_{j}\right)=\theta+\gamma x_{j}+\frac{1}{2} \delta x_{j}^{2}
$$

The firms face a linear inverse market demand curve:

$$
p_{x}=a-b X
$$

where $X$ is the total quantity of gear produced, $X=\sum_{k} x_{k}=x_{j}+\sum_{k \neq j} x_{k}$.

Profits for firm $j$ are:

$$
\left[a-b\left(x_{j}+\sum_{k \neq j} x_{k}\right)\right] x_{j}-\theta-\gamma x_{j}-\frac{1}{2} \delta x_{j}^{2} .
$$

Maximizing these profits with respect to $x_{j}$, and taking the production of other firms $x_{k}$ as given, the firstorder condition for the firm is to set marginal revenue equal to marginal cost, or:

$$
a-2 b x_{j}-b \sum_{k \neq j} x_{k}=\gamma+\delta x_{j}
$$

Assuming a symmetric equilibrium, then we have $x_{k}=x_{j}$, or, for each firm $j$ :

$$
\begin{gathered}
a-b(J+1) x_{j}=\gamma+\delta x_{j} \\
x_{j}^{*}=\frac{a-\gamma}{\delta+b(J+1)} .
\end{gathered}
$$

The total quantity is $J$ times this value, or

$$
X^{*}=\frac{(a-\gamma) J}{\delta+b(J+1)}
$$

Finally, the equilibrium price is given by substituting this equilibrium quantity back into the inverse demand function, $p_{x}^{*}=a-b X^{*}$ :

$$
p_{x}^{*}=a-b \frac{(a-\gamma) J}{\delta+b(J+1)}
$$


Consider next the question, how does the gear tax affect this equilibrium? As always, we can model an excise tax, in isolation, by shifting the demand curve down by an amount $t$, effectively replacing $a$ with $a-t$ in the demand curve and in the equilibrium price and quantity. Since the revenue is used to enhance quality of one or more parks, following our analysis in Section 3, we can view this effect, to a first-order approximation, as a parallel shift up in the demand curve for gear. Denote the net effect of these two parallel shifts as $d a$ (the change in the intercept of the demand curve).

At the margin, the net effect of this tax/quality enhancement on the equilibrium quantity is $d X^{*}=$ $\frac{\partial X^{*}}{\partial a} d a$, or:

$$
d X^{*}=\frac{J}{\delta+b(J+1)} d a
$$

This term will have the same sign as $d a$. Thus, if the net effect is to shift demand up, the equilibrium quantity demanded and quantity supplied increases in the Cournot model. By the same token, the change in price is $d p_{x}^{*}=\frac{\partial p_{x}^{*}}{\partial a} d a$, or

$$
d p_{x}^{*}=\left[1-\frac{b J}{\delta+b(J+1)}\right] d a
$$

And this price change also is the same sign as $d a{ }^{11}$

Thus, firms are clearly better off: A shift up in the demand curve leads to higher sales and higher prices, which increases profits. Thus, even though they bear some of the burden of the tax per se, firms benefit if the feedback effect of the quality improvement on demand is sufficiently large.

What about consumers? Consider the Marshallian consumer surplus in this market, $\mathrm{CS}=\frac{1}{2} X^{*}\left(a-p_{x}^{*}\right)$. Substituting in the above expressions for $X^{*}$ and $p_{x}^{*}$, we have:

$$
C S=\frac{1}{2}\left[\frac{(a-\gamma) J}{\delta+b(J+1)}\right]\left[b \frac{(a-\gamma) J}{\delta+b(J+1)}\right]=\frac{b}{2}(a-\gamma)^{2}\left(\frac{J}{\delta+b(J+1)}\right)^{2} .
$$

If we consider how the consumer surplus changes with $a$ (i.e. $d C S=\frac{\partial C S}{\partial a} d a$ ), we have:

$$
d C S=b(a-\gamma)\left(\frac{J}{\delta+b(J+1)}\right)^{2} d a
$$

Again, this change in consumer surplus is the same sign as $d a$ (assuming an interior solution where the demand curve intersects the supply curve, which occurs where $a>\gamma$ ). Thus, consumer surplus also increases if the demand curve increases.

${ }^{511}$ Note that if $\delta=0$ we would have $1-J /(J+1)>0$ in brackets; but the term in brackets is increasing in $\delta$. 
Moreover, as perfect competition and a single-price monopoly are special cases of Cournot with $J=\infty$ and $J=1$, respectively, the result holds in those limiting cases as well.

Of course, we usually measure consumer welfare with Hicksian surplus, not Marshallian consumer surplus. Since we are using a first-order approximation in terms of price, we are effectively assuming the price/ quality relationship is not affected by income (and thus we are implicitly using the Willig condition, along with weak complementarity in this argument).

Proposition 3. Under weak complementarity and the Willig condition, and under Cournot competition, perfect competition, or monopoly pricing, to a first-order approximation, welfare increases for both consumers and sellers from a combination of a dedicated gear tax and the implied corresponding increase in public good services if and only if the Marshallian quantity demanded for gear increases on net.

In sum, the test is the same as that from Section 2: To a first-order approximation, our gauge of the effects is still given by Expressions (7) or (8):

$$
t<\frac{\pi}{x} \frac{N x t}{p_{q}}
$$

$$
p_{q}<N \pi
$$

The demand curve shifts down by $t$ and shifts up by the value of $q$ per unit of gear $\pi / x$ times the change in $q$ that is consistent with the increased revenues or given our simplifying assumptions $N x t / p_{q}$. So, to a first-order approximation, we still have a gauge of whether $p_{q}<\pi N$, for gear as well as for trips. ${ }^{12}$

\section{REFLECTIONS ON BUNDLING}

The argument that a public good funded with a dedicated tax can make households better off is not new. The conclusion that it can make firms better off too may be more surprising. The potential for this result stems from the bundling made possible by weak complementarity, which increases the demand for the taxed good. It relies on the strength of the link between the public good and its weak complement as well as being able to increase the public good services sufficiently, given the extent of the market for that private good. Potentially, this linkage creates incentives for entrepreneurs to contribute to the public good by bundling it to private goods (Anderson [1998], Anderson and Leal [2001], Anderson and Parker [2013], Banzhaf, Fitzgerald, and Schnier [2013], Chichilnisky and Heal [1998], Heal [2000, 2003]). One prominent example is ecotourism. When tourists visit a preserve in southern Africa to view (or hunt) elephants and other wildlife, they cannot obtain that value unless they also consume a linked private good, such as a guided safari or a stay at a lodge. Furthermore, because they do not enjoy the ecosystem services unless they also purchase those private goods, they can effectively be excluded from enjoying

\footnotetext{
12 Of course, whether the test is met is an empirical question. Walls (this issue) argues that the own-price elasticity of gear is probably quite high, meaning that the quantity demanded is likely to fall. However, she does not consider the complementarity between gear and the investment funded by the dedicated tax.
} 
the ecosystem as well. Thus, the access conditions for the private good define the extent of the market for the public good as well. Similarly, when the wildlife is better, the demand for the safaris is higher. Consequently, the safari guide has an incentive to conserve and maintain elephant habitat. The South African company andBeyond (formerly Cons-Corp) does precisely this; buying up land from ranchers that is far more valuable as elephant habitat (Anderson [1998], Heal [2000]).

In his analysis of such incentives, Heal (2003) identifies three necessary conditions. The first is weak complementarity. The second is that the private good be sold by a monopolist. This condition is important because it evades the "free rider" problem in the provision of the public good. For example, when the outfitter invests in improving the ecosystem services of the park, as a lone seller it would capture the full benefit of the increased demand for trips to the park, so it has the full incentive to make the investment. With many sellers, this is no longer true. Each of them would benefit from an improvement in ecosystem services but would prefer to let the others bear the expense of the improvement.

Heal's third condition is not only that the private good be sold by a monopolist, but that it be sold by a perfectly price discriminating monopolist. Thus, for goods that sell in varying quantities, the seller can offer an "all-or-nothing deal" for a specific quantity that leaves the customer just indifferent to buying the bundle or not. This third condition completes a syllogism at the heart of Heal's logic:

- By weak complementarity, the Hicksian value for an investment in the public good is equal to the change in the Hicksian value for the linked private good.

- Because it is a perfectly discriminating monopolist, the seller can capture the full Hicksian value of the private good.

- Therefore, the seller captures the full Hicksian value of the investment in the public good.

Thus, in Figure 1, the seller's marginal increase in profits from an improvement in the public good is the same as the shaded area marked as the social benefit. This area is equivalent to the area marked in Figure 2. Comparing this area to the cost of the investment, the seller provides the public good up to the optimal level, $q^{*}$.

Our analysis of the gear tax is similar, insofar as the value is potentially created through investments in natural resources and captured by private sellers of a linked weak complement. It differs in that, because the seller is not a monopolist, there is the potential for free riding. But taxes are a standard way to overcome such free-rider problems. In this case, if sellers of gear would benefit jointly from increased investment in public lands, the gear tax would represent a kind of compact or coordinating mechanism that assures they participate. An analogy might be made to commodity checkoff programs, where dairy farmers pay collectively for an ad campaign ("got milk?") that benefits the group.

This possibility parallels other, more familiar, situations where demand for a private good is higher because it is taxed, with the revenue ploughed back into a complementary public good. Vehicles and roads are weak complements: One doesn't value the maintenance of roads unless one drives a vehicle. Total driving is probably greater because of the gas tax and the road improvements it funds (relative to a counter-factual without that transportation funding). Likewise, housing in a community and its public 
schools and other local services are weak complements. Housing demand is surely higher in an area with a property tax than it would be if there were no tax and no public services. Finally, and closest in theme, the Pittman-Robertson program which taxes hunting and fishing equipment to support public lands is popular both with industry and hunters and anglers. They want to be taxed, so long as the revenue is reinvested into maintaining the resources they use. In the same way, sellers of gear might benefit from being taxed if the money is reinvested in the parks and if the complementarity between gear and the services provided by the investment is strong enough.

\section{Relaxing Weak Complementarity}

Till now, we have maintained two assumptions about the relationship between the private good being taxed (trips or gear) and the public good to which the resulting increased revenue is dedicated. The first is weak complementarity. As noted previously, this assumption rules out non-use values. The assumption is arguably most fitting when the revenue is used for services that specifically support recreation (trail maintenance, camp sites, etc.). If fees are used to support habitat or protect water quality at unique sites like Yellowstone or the Grand Canyon, however, non-use values may need to be considered. Their relevance depends on how the revenue is used. If the revenue enhances services arguably separate from what underlies nonuse values, then the omission is less important.

Weak complementarity may seem less applicable to the case of gear. Even here, though, we hasten to emphasize that weak complementarity implies only that households have, e.g., no value for trail maintenance if they do not have hiking boots, not symmetrically that they do not value the boots without the trail work. In this sense, we suggest the issue is not so much whether there is weak complementarity. Rather, the issue is whether it is strong enough to assure the feedback effects on demand for the taxed goods due to the enhancement of the public good will offset the price increases. In the case of outdoor recreation, several types of gear as well as transportation all might serve together as a bundle of weak complements to environmental amenities. In this case, an analogous sum of the sequential changes in consumer surplus for all the weak complements would equal the value for the investment (Bockstael and Kling 1988). The issue then becomes whether the value in the taxed markets is high enough that it can be captured by sellers, even if there is no nonuse value.

A similar issue arises from our first-order approximation, which basically assumed demand curves for the private weak complement shift up vertically. In principle, weak complementarity only requires that they shift up over some portion of their domain. It is possible that they could shift up infra-marginally, but not at the margin. Greater public good services may increase the number of times a recreationist uses the boots or the fly rod and/or increase the value of each use, but not the number of pairs of boots or fishing rods. That is, an investment in public lands increases the consumer surplus for boots, but not necessarily the quantity demanded. Without non-linear pricing, capturing such value will be challenging.

If these effects are non-negligible, then some social value is not captured by sellers in the linked private market. In that case, our result is a sufficient but not necessary condition: If the demand for the weak 
complement increases, then there is a Pareto improvement, but the converse is not true. Thus, our approach essentially identifies a lower bound on values.

One last consideration bears on the ability of firms to capture some of this value, even non-use value: The desire to make voluntary contributions to public lands. Even some non-use value may be captured by sellers of a private good if consumers are willing to donate to public lands and view the higher prices as an indirect mechanism for such donations. For example, organizations like REI and Patagonia donate revenue to preserving environmental amenities. With the gear tax, one could imagine stickers on taxed goods proclaiming "t\% of every dollar goes to funding public lands." Kotchen $(2005,2006,2013)$ refers to such situations as "mixed public goods", which bundle an excludable private good (like gear) with a contribution to a public good. Individuals can be excluded from the private good but not the non-use values for the public good, which they enjoy whether they buy the linked private good or make the donation or not. However, if they are partly motivated by the good feelings of making the donation ("warm glow"), even indirectly by buying a good where some of the revenues are donated, then they can be excluded from that part of the package. They cannot receive the satisfaction of making a donation unless they actually donate, which is itself a form of weak complementarity (Banzhaf, Fitzgerald, and Schnier 2013). This argument suggests we now have three effects shifting the demand curve: The tax shifting it down, the public services shifting it up because the benefit from using it in recreation activities is higher, and the fact that the purchase represents a donation also shifting it up. This last effect creates a different "extent of the market"-people who may not be as concerned about how much their personal recreation experience is enhanced but do gain nonetheless by knowing they "did their part" to sustain the parks.

\section{Empirical Evidence}

Despite the extensive economic literature on outdoor recreation, we know surprisingly little about some of the questions posed in this paper. For sixty years, the workhorse model of recreation valuation has been the travel cost model, in which travel costs are meant to simulate the effect of a gate fee. ${ }^{13}$ While well positioned to address some of our questions, to date the travel-cost literature has focused on consumer surplus, ignoring the revenue actually collected by the gate fee. It also has tended to focus on questions associated with the valuation of natural amenities, with less emphasis on how the amenities can be maintained or enhanced with the revenue.

For the gear tax, the empirical challenges are even greater. The central empirical challenge we face is developing estimates for how the improvements in park quality would affect the demand for recreational gear. This effect underlies the shift in demand we described in Figure 4. Critically, data do not include measures for the activities involved with the gear or the locations where the gear was used. Thus, making the connection between park quality and gear is difficult. When park use has been studied in recreation

\footnotetext{
${ }^{13}$ See Phaneuf and Smith (2005) and Lupi, Phaneuf, and von Haefen (2020) for reviews of this literature.
} 
demand studies, the quality features considered are usually not related to the ones that might be affected by the activities associated with how parks are maintained. As a result, we selected two sets of estimates for the value of national parks and adapted them in an approximate way to develop estimates of the value share, which can be used to implement the logic implied by equation (5).

With some substitutions, we can rewrite Expression (5) in percentage terms, making it more useful for use with the available data:

$$
\frac{t}{p_{x}^{0}}<\frac{\pi q^{0} / m}{p_{x}^{0} x / m} \cdot \frac{\Delta q}{q^{0}}
$$

This expression gives us a starting point for determining a neutral tax from the perspective of the representative household. In our setting, we do not know $p_{x}^{0}$, so we do not know whether the enhancement in the public good can be paid for the revenues raised by the increased gate fees or gear tax. However, we can still find the critical value $t^{*}$ that would be necessary to leave households indifferent. A proportionate tax of $t / p_{x}^{0}$ that is less than what is implied by the right side of equation (9) would improve welfare for a representative household.

In other words, by comparing the value share for the services associated with park quality as a fraction of income $\left(\pi q^{0} / \mathrm{m}\right)$ to the share of income spent on gear $\left(p_{x}^{0} x / m\right)$, we have a gauge of how much the price can increase (due to the tax) for each percentage point increase in quality. For example, if the value share for park quality is about $1 \%$ of income and expenditures on gear about $2 \%$, then the price increase that would hold willingness to pay constant for a representative individual (with simultaneous improvements in park quality) would be half the percentage increase in quality. Larger value shares for park quality would allow for larger price increases.

In this section, we provide some suggestive evidence on the range of price increases for a given improvement in park quality that would be WTP neutral, as we defined this idea in Section 3. Our estimates leverage some diverse sources for estimates of the components of equation (9). They mix data from different household samples and different time periods. As a result, they are best viewed a "collage of estimates" that were collected to match up available information with the task at hand and should be interpreted as illustrative examples of what could be done once there are better data. If the logic associated with our ratio of shares proves useful, then implementing it will require a more extensive effort to assemble consistently defined measure for each of the shares.

The first parameter we require is the income-share of park quality, $\pi q^{0} / m$. To estimate this parameter, we use both revealed preference and stated preference results in the literature. The results for the revealed preference study we selected (Parsons et al. [2018]) are in the top panel of the Table 1. The first column provides the names for each of the Southwestern Parks included in this study. The second column provides the estimate reported in the study for the willingness to pay to avoid removing one of the parks from a set that was visited as a group during a vacation trip. Essentially the study assumed each visit was part of a planned trip that included visits to multiple sites. The data were collected with on-site surveys in 
each of the seven parks considered as part of the study. Initial contacts were made to potential survey respondents in the parks as they entered during a specific time window, and then these individuals were sent follow up surveys to collect the specific data used in the analysis. Our results are taken from one of the models reported in Parsons et al. (2018), a standard random utility model where the choice set involved different portfolios of parks to be visited. The model assumes the trip is undertaken and the choice set is among a group of alternative portfolios that each involve a distinct mix of Southwestern Parks. This process served to define a composite of multiple site choice alternatives. The costs then correspond to the costs associated with altering the mix of sites, given the respondent has already taken the trip.

\section{Table 1. Estimates of the Willingness-to-Pay-Neutral Scaling Factor}

\begin{tabular}{|c|c|c|c|c|c|c|}
\hline & $\begin{array}{c}\text { AVERAGE } \\
\text { LOSS PER } \\
\text { USER BY PARK }\end{array}$ & $\begin{array}{l}\text { SHARE } \\
\text { OF } \\
\text { INCOME }\end{array}$ & $\begin{array}{c}\text { CAMPING } \\
\text { EXPENDITURES }\end{array}$ & $\begin{array}{c}\text { HIKING } \\
\text { EXPENDITURES }\end{array}$ & MOUNTAIN & $\begin{array}{l}\text { WILDLIFE } \\
\text { VIEWING } \\
\text { EXPENSES }\end{array}$ \\
\hline \multicolumn{7}{|c|}{ Parsons et al (2018) 2002\$ } \\
\hline $\begin{array}{l}\text { Gear Expenditure } \\
\text { Share of Income }\end{array}$ & & & 0.0044 & 0.0030 & 0.0030 & 0.0100 \\
\hline Southwest Parks & & & & & & \\
\hline Arches & 185 & 0.0136 & 3.109 & 4.481 & 2.359 & 1.355 \\
\hline Bryce & 174 & 0.0135 & 3.075 & 4.433 & 2.334 & 1.340 \\
\hline Canyonlands & 150 & 0.0131 & 3.001 & 4.326 & 2.277 & 1.308 \\
\hline Grand Canyon & 227 & 0.0142 & 3.239 & 4.668 & 2.458 & 1.411 \\
\hline Mesa Verde & 165 & 0.0133 & 3.047 & 4.392 & 2.313 & 1.328 \\
\hline Petrified Forest & 141 & 0.0130 & 2.973 & 4.286 & 2.256 & 1.296 \\
\hline Zion & 186 & 0.0136 & 3.112 & 4.486 & 2.362 & 1.356 \\
\hline Household Income & \multicolumn{6}{|c|}{ Haefele, Loomis and Bilmas (2020) 2014\$ } \\
\hline $\begin{array}{l}\text { Avoiding Sale of in } \\
\text { Nature Based } \\
\text { National Parks }\end{array}$ & 1,113 & 0.0177 & 4.039 & 5.822 & 3.065 & 1.760 \\
\hline $\begin{array}{l}\text { Avoiding Sale of in } \\
\text { Water Based National } \\
\text { Parks }\end{array}$ & 978 & 0.0155 & 3.549 & 5.116 & 2.693 & 1.546 \\
\hline $\begin{array}{l}\text { All National Parks } \\
\text { Household Income }\end{array}$ & $\begin{array}{c}2,967 \\
63,000\end{array}$ & 0.0471 & 10.768 & 15.520 & 8.171 & $\begin{array}{c}4.692 \\
79,000\end{array}$ \\
\hline
\end{tabular}

The measure we selected for willingness to pay considers a situation where the model is calculating the amount that would be paid to avoid removing each site, one at a time, from the portfolio. Our estimate is the average for each site over all possible combinations considered for the portfolios and for all of the respondents in the sample in 2002\$. To arrive at the value share for each site as part of an annual vacation, we added the incremental willingness to pay as defined in the analysis (given in the second column) for the park to the average trip expenditures for the vacation from the sample (\$822) and compare this estimate to an estimate of the average respondents' income. The results are shown in the third column of Table 1 . These are our estimates of $\pi q^{0} / m$ for each park. Thus, the numerator is a measure of the contribution of an individual park, as a "quality" indicator for an overall recreation trip that included visiting multiple parks. We recognize this interpretation is a "stretch." It is required because 
the revealed preference literature does not appear to have better measures for how the maintenance of a park contributes to the quality of a recreation trip composed of visiting Southwestern parks. As a result, we pose a thought experiment. If quality declines associated with lack of maintenance would eliminate a park from a recreationist's planned portfolio, how much would that person pay to support the maintenance?

The second set of information required for our ratio in equation (9) is the share of income for recreational gear, $\left(p_{x}^{0} x / m\right)$. We use two sources to estimate the share. The first is an Outdoor Recreation Association (2017) study. The study uses a pre-existing, large, internet panel to provide a representative sample and asks about expenditures on recreation equipment and participation in thirty-eight activities. Their analysis involved a national survey in 2016 of spending on recreation gear for each of 38 activities. We selected three non-motorized activity groups to construct the share measures-camping, hiking, and mountaineering. Camping includes trips that involve sleeping in a tent or in a lodge; hiking was defined as a day hike; and mountaineering corresponded to a composite of three activities, backpacking, mountaineering, and rock or ice climbing. The report did not include household incomes of the respondents. To convert these values to expenditure shares, we use the 2016 median household income as reported by the St. Louis Federal Reserve Bank. ${ }^{14}$ These annual shares are given for each of the three activities in the second row of the table.

Our estimated expenditure share for wildlife viewing was taken from a different source. ${ }^{15}$ We use the 2016 National Survey of Fishing Hunting and Wildlife Associated Recreation. This survey reports equipment expenditures including both for those involving trips around the home and away from the home. We consider the total of these expenditures, omitting trip related expenses, for our measure of gear related expenses. Median household income for those undertaking wildlife viewing away from home was used to compute these ratios. These estimates are also reported in the second row of the table.

The remaining cells in the top panel of Table 1 can then be interpreted as a matrix, with each row corresponding to one value of $\pi q^{0} / m$ and each column corresponding to one value of $p_{x}^{0} x / m$. Each cell in the matrix computes the ratio of the two, as used in equation (9). All the estimates exceed unity, implying the tax, in percentage terms, can exceed the quality improvement for parks in percentage terms. The analysis does not consider whether the revenue raised would be sufficient to pay for the increase in quality. We consider these estimated ratios as alternative measures for the scaling factor we defined for computing the willingness to pay neutral price increase for gear. Each provides an alternative estimate, depending on which of the Southwest parks and type of gear measures was considered most plausible, as an example that best fits the logic underlying equation (10). The measures for wildlife viewing are the smallest, but still imply taxes, in percentage terms, could be 30 to 40 percent larger than the percentage

\footnotetext{
14 The estimate for median income we used was $\$ 58,988$ in 2016 dollars. See https://fred.stlouisfed.org.

15 The report did indicate expenditures on wildlife viewing were elicited but did not report them, presumably because the percentage participation was small.
} 
improvement in park quality. If we consider the activity specific gear measures, where the income shares are smaller, the increases can be as large as 4.5 times the percentage improvement in quality.

The second panel in the table repeats the logic with a different source for the measure of the value share for park quality, the Haefele et al. (2020) stated preference study for alternative proposals to address the need for added park funding. This study uses a national sample, not one based on on-site sampling as was the case for the above revealed preference estimates. The contingent valuation question presents alternative policies to reduce the size of the park system by selling different amounts of parks, presented in terms of acres or sites sold, as a composite including nature based, historic, and water based parks with these terms and the total amounts defined in the survey. The nature-based and water-based groups are presented as lost acres (from the sales), implying portions of the park acres would be sold off, not necessarily individual parks. For the historic category of parks, the amount sold is presented as sites sold.

Three alternative sets of losses, along with an annual income tax increase to avoid the policy are presented in the first choice question. ${ }^{16}$ Each respondent is asked to indicate their most preferred and their least preferred alternatives. The option of no change in parks is included with the largest required tax increase of the three presented to each respondent. Separate amounts of tax increase were set for the no sales case, ranging from $\$ 115$ to $\$ 600$. For the cases with sales the amounts sold ranged from 20 to $40 \%$. For the maximum case and the amount of the tax increase was always zero. The middle case was a smaller amount of sales, zero to ten percent, and smaller tax increases, $\$ 15$ to $\$ 100$. Fifteen different combinations varying the percentages sold and tax amounts with the restrictions on the tax amount for the largest amount sold and for the no sale cases imposed. A rank logit estimator was used to estimate the willingness to pay measures.

The estimates developed for each policy alternative are based on using the estimated parameters from the model to compute a marginal willingness to pay and rescaling that measure by the amount (in acres or sites) for the alternative considered. This "unit value" was then the basis for the willingness to pay measures reported in the bottom panel in Table 1 for this study. Many questions could be raised about the implicit assumptions in this somewhat ad hoc benefit transfer strategy to develop these estimates. Due to the limited number of available estimates, we simply used their estimates for willingness to pay and median income as another alternative basis for the measuring the park quality share.

As expected, given the difference in the object of choice used to measure the numerator of our willingness to pay neutral scaling factor, these ratios are dramatically larger than those based on the Parsons et al. (2018) study of specific Southwestern parks. Neither study ideally matches our needs. This set of estimates, taken as a whole, provide an approximate range of what to expect for the willingness-topay-neutral scaling factor. Given that the scale of the deferred maintenance and associated park quality is large, small overall improvements in the quality of the system are the likely result of any new funding source. Nevertheless, these "rough" estimates suggest a larger price increase (in percentage terms)

\footnotetext{
${ }^{16} \mathrm{~A}$ second choice question explained as independent was asked about different cutbacks in park programs.
} 
would not be inconsistent with a WTP-neutral effect, provided they actually raised sufficient revenue to support the quality enhancements. The implication of this assessment is that, based on the logic outlined in Figure 4, taxes that, as a percent of gear prices, are larger than the park quality increases in percentage terms can still increase welfare for both buyers and sellers.

\section{Concluding Discussion}

Our empirical analysis in Section 6 illustrates how our approach to dedicated taxes can be implemented in practice. However, our experience with it has highlighted how far the otherwise advanced literature on recreation demand currently is from addressing the questions posed here. Four areas stand out as needing additional attention. First, better, more detailed data is needed on the actual projects for which public lands need (or claim to need) funding. We attempted to obtain park-level maintenance information and were told these data did not exist in convenient form and would be difficult to develop. Second, while travel and other costs incurred by the user are well studied, more information is needed on the cost of a user-day on public lands. One of the first comprehensive analyses of the economics of outdoor recreation by Clawson and Knetsch (1966) devoted two sections to analysis of the costs, but provided only general descriptions of the economic principles underlying cost analysis without specific attention to the measurement of output and how that impacts the treatment of inputs and costs. The CRS (2019) discussion of deferred maintenance defines maintenance to "...include a variety of activities intended to preserve assets in an acceptable condition, including activities such as preventative maintenance and replacement of parts, systems, and components" (p. 1). ${ }^{17}$ The average cost per userday and how it differs at the margin would be useful for setting optimal fees.

Third, more consideration should be given to the political economy of fees and taxes. Policy must address the diverse sources of revenue within an agency and the way that revenue is shared across individual units. For example, Congressional appropriations for each of the 419 units of the NPS are line items in its overall appropriation. These allocations cannot be altered by the Secretary of Interior or the Director of the National Park Service. Additional revenue sources may change those appropriations or the way they are allocated across sites. Gate fees at least have the potential to be kept local, keeping the finance mechanism closer aligned with the benefit principle and preserving incentives for managers to run their facilities well. In the case of gear, such subsidies are more likely, as presumably it would be taxed at a national level and then distributed. How revenue would be shared and the incentives those sharing rules create would be crucial for understanding the effects of policy, but our analysis here abstracts from these questions.

Finally, despite over 50 years of travel cost modeling, the literature on the economic value of public lands almost entirely ignores the incremental value of mundane investments in $M \& O$ that are the actual everyday concern of managers. It also ignores questions about revenue. Instead, it focuses almost

\footnotetext{
${ }^{17}$ It is our understanding the NPS currently is reforming its methodology for measuring deferred maintenance (personal discussion between Smith and Charles Notzon of the NPS, 10/25/2019).
} 
exclusively on the consumer surplus for the existence of a site, or perhaps improvements in water quality or air quality. Benefit studies appear to be driven more by efforts to illustrate new methods than to obtain measures of trade-offs for specific policy questions.

Estimates of marginal values for other types of investments, along with their cost, could help park managers with specific decisions. We have shown that, when public goods are bundled together to a private weak complement, there is a very simple test for whether a gate fee reinvested in the public good will increase welfare: Namely, that the demand for the private good shifts up on net. A similar test implies both consumers and sellers of a private good would benefit from a gear tax.

Our application took a public-finance perspective on the management of public lands. However, the same approach could be applied to a marketing perspective for private lands or monopoly-owned weak complements. Interestingly, weak complementarity has been used in two distinct literatures, which to our knowledge have not previously been connected. First, it has been used in non-market valuation for purposes of benefit-cost analysis (Mäler 1974). Second, it has been used in the analysis of private incentives to provide public goods (Anderson and Parker 2013, Heal 2003). Our theoretical analysis of the gear tax synthesizes these two perspectives. If there is a way for an analyst to estimate value from market behavior, then there is a way for entrepreneurs and markets to capture that value. Thus, weak complementarity plays a role in "bottom-up" (Hayekian) as well as "top-down" (Lange-Lerner) approaches to value. 


\section{References}

Anderson, Terry L. 1998. "Viewing Wildlife through Coase-Colored Glasses." In Who Owns the Environment?, ed. By Peter J. Hill and Roger Meiners. Lanham, MD: Roman \& Littlefield, pp. 25982.

Anderson, Terry L., and Donald R. Leal. 2001. Free Market Environmentalism, $2^{\text {nd }}$ ed. New York: Palgrave.

Anderson, Terry L., and Dominic P. Parker. 2013. "Transaction Costs and Environmental Markets: The Role of Entrepreneurs." Review of Environmental Economics and Policy 7(2): 259-75.

Banzhaf, H. Spencer, Timothy Fitzgerald, and Kurt Schnier. 2013. "Nonregulatory Approaches to the Environment: Coasean and Pigouvian Perspectives." Review of Environmental Economics and Policy 7(2): 238-58.

Bockstael, Nancy E., and Catherine L. Kling. 1988. "Valuing Environmental Quality: Weak Complementarity with Sets of Goods." American Journal of Agricultural Economics 70(3): 654-62.

Bockstael, Nancy E., and Kenneth E. McConnell. 1993. "Public Goods as Characteristics of Non-Market Commodities." Economic Journal 103: 1244-57.

Chichilnisky, Graciela, and Geoffrey Heal. 1998. "Economic Returns from the Biosphere." Nature 391: 62930.

Congressional Research Service (CRS). 2015. "Federal Lands Recreation Enhancement Act: Overviews and Issues."

Congressional Research Service (CRS). 2019a. "Deferred Maintenance of Federal Land Management Agencies: FY2009-FY2018 Estimates and Issues" updated April30. R43997

Congressional Research Service (CRS). 2019b. "Land and Water Conservation Fund: Appropriations for "Other Purposes" updated May 14. R44121

Congressional Research Service (CRS). 2019c. "National Park Service Appropriations: Ten Year Trends" (author Laura B. Comay) updated July 2. R42757.

Fretwell, Holly Lippke. 1999. "Paying to Play: The Fee Demonstration Program." PERC Policy Series PS-17.

Haefele, Michelle, John Loomis, and Linda J. Bilmes. 2020. "Total Economic Valuation of the National Park Service Units and National Park Service Cooperative Programs." In Valuing U.S. National Parks and Programs: America's Best Investments, ed. by Linda J. Bilmes and John B. Loomis. New York: Earthscan from Routledge, pp 16-44.

Heal, Geoffrey. 2000. Nature and the Marketplace: Capturing the Value of Ecosystem Services. Washington, DC: Island Press. 
Heal, Geoffrey. 2003. "Bundling Biodiversity." Journal of the European Economic Association 1(2-3): 553-

60.

Kotchen, Matthew J. 2005. "Impure Public Goods and the Comparative Statics of Environmentally Friendly Consumption." Journal of Environmental Economics and Management 49: 281-300.

Kotchen, Matthew J. 2006. "Green Markets and Private Provision of Public Goods." Journal of Political Economy 114(4): 816-34.

Kotchen, Matthew J. 2013. "Voluntary- and Information-Based Approaches to Environmental Management: A Public Economics Perspective." Review of Environmental Economics and Policy 7(2): 276-95.

Lindahl, Erik.1958. "Just Taxation -A Positive Solution" (English translation). In Classics in the Theory of Public Finance, edited by R.A. Musgrave and A.T. Peacock. London: Macmillan.

Loomis, John B., and Rodney W. Olson. 1985. "Potential Federal Funding of State Nongame Management Programs: Results of a US Fish and Wildlife Service Study." Transactions of the North American Wildlife and Natural Resources Conference 50: 374-82.

Lupi, Frank, Daniel J. Phaneuf, and Roger von Haefen. 2020. "Best Practices in Recreation Demand Analysis." Review of Environmental Economics and Policy, forthcoming.

Madden, Paul. 1991. "A Generalization of Hicksian q Substitutes and Complements with an Application to Demand Rationing." Econometrica 59(5): 1497-1508.

Mäler, Karl Göran. 1974. Environmental Economics: A Theoretical Inquiry. Baltimore: John Hopkins University Press for Resources for the Future.

Musgrave, Richard A. 1959. The Theory of Public Finance: A Study in Public Economics. New York: McGraw Hill Book Co.

Myles, Gareth D. 1995. Public Economics. New York: Cambridge University Press.

Outdoor Recreation Association. 2017. The Economic Contributions of Outdoor Recreation: Technical Report on Study Scope, Methods, and Procedures. Fernandina Beach, FL: Southwick Associates, August.

Parsons, George, Chris Leggett, Joseph Herriges, Kevin Boyle, Nancy Bockstael, and Zoe Chen. 2018. "A Site-Portfolio Model for Multiple-Destination Recreation Trips: Valuing Trips to National Parks in the Southwestern USA." Unpublished paper. December.

Phaneuf, Daniel J., and V. Kerry Smith. 2005. "Recreation demand models." In Handbook of Environmental Economics, Vol. 2, ed. by Karl-Göran Mäler and Jeffrey R. Vincent. (Elsevier)Pp. 671-761.

Ramsey, Frank P. 1927. "A Contribution to the Theory of Taxation." Economic Journal 37:47-61. 
Smith, V. Kerry, and H. Spencer Banzhaf. 2004. "A Diagrammatic Exposition of Weak Complementarity and the Willig Condition." American Journal of Agricultural Economics 86: 455-66.

Smith, V. Kerry, and H. Spencer Banzhaf. 2007. "Quality Adjusted Price Indexes and the Willig Condition." Economics Letters 94: 43-48

US Department of the Interior (US DOI). 2018a. "Certificate of Apportionment of $\$ 797,160,562$ of the appropriation for Pittman-Robertson Wildlife Restoration (CFDA No. 15.611)..." Memorandum FWS/AWSR/AIM:067398. March 20, 2018.

US Department of the Interior (US DOI). 2018b. "Certificate of Apportionment of $\$ 351,917,483$ of the appropriation for Dingell-Johnson Sport Fish Restoration (CFDA No. 15.605)..." Memorandum FWS/AWSR/AIM:067398. March 20, 2018.

U.S. Department of the Interior, U.S. Fish and Wildlife Service, and U.S. Department of Commerce, U.S. Census Bureau. 2016. 2016 National Survey of Fishing, Hunting, and Wildlife-Associated Recreation.

U.S. Forest Service. 2017. 2018 Budget Overview. https://www.fs.fed.us/sites/default/files/ usfs-fy18-budget-overview.pdf.

U.S. Government Accountability Office (GAO). 2016. National Park Service: Process Exists for Prioritizing Asset Maintenance Decisions, But Evaluation Could Improve Efforts. Report to Congressional Requesters, December, GAO-17-136

U.S. National Park Service. 2018. National Park Service Fiscal Year 2018 Budget Justifications. https://www.nps.gov/aboutus/upload/FY-2018-NPS-Greenbook.pdf.

Walls, Margaret. 2013. Paying for State Parks: Evaluating Alternative Approaches for the 21st Century, Resources for the Future Report, January.

Williams, Steve. 2010. "Wellspring of Wildlife Funding: How Hunter and Angler Dollars Fuel Wildlife Conservation." The Wildlife Professional (Fall): 35-38.

Willig, Robert D. 1978. "Incremental Consumer's Surplus and Hedonic Price Adjustment." Journal of Economic Theory 17(2): 227-53. 


\section{About the Authors}

H. Spencer Banzhaf is a professor in the Andrew Young School's Department of Economics. Banzhaf's research focuses on environmental economics and policy analysis. More narrowly, much of his work studies the interactions between local environmental amenities, local real estate markets, and the demographic composition and structure of cities. He applies these and other tools of benefit-cost analysis to the evaluation and design of environmental policy and to the creation of "green" index numbers and accounts. He also studies the history of welfare economics. Banzhaf's work has been published in journals such as the American Economic Review, International Economic Review, Journal of Applied Econometrics, Journal of Environmental Economics and Management, Journal of Urban Economics, and History of Political Economy.

V. Kerry Smith is an Emeritus Regents Professor and an Emeritus University Professor of Economics and a Distinguished Sustainability Scientist in GIOS at Arizona State University. A member of the National Academy of Sciences, his research considers environmental policy issues. A University Fellow at Resources for the Future, and a Research Associate with the National Bureau of Economic Research, he came to ASU from North Carolina State University in 2006 where he was the University Distinguished Professor and was Director of the Center for Environmental and Resource Economic Policy. Prior to North Carolina State, he held positions as the Arts and Sciences Professor of Environmental Economics at Duke and the Centennial Professor of Economics at Vanderbilt. He is a Fellow of the Association of Environmental and Resource Economists and a Fellow of the American Agricultural Economics Association. He has advised federal and state agencies in the U.S., Canada, and other countries on the assessment of economic values for nonmarket environmental resources. 